\title{
The Design for the Teaching Aid in English Class Based on Solidwork
}

\author{
Wan Yi \\ School of Foreign Languages \\ Northeast Petroleum University \\ Daqing PR China \\ e-mail:Wanyi331@126.com
}

\author{
Xiuling Ren \\ School of Mechanical Science and Engineering \\ Northeast Petroleum University \\ Daqing PR China \\ e-mail: xiulingren@126.com
}

\begin{abstract}
The teaching aid in English class was designed based on SolidWorks2010. The processing for generation of teaching aid is discussed, and the distribution of the stress, strain and displacement is investigated with different load. The results indicate that the node number of the teaching aid is approximately 28120, and the grid unit number is 18035 . When the load of the teaching aid is $10 \mathrm{~N}$ and $20 \mathrm{~N}$, respectively, the max stress is $2.995 \mathrm{~N} / \mathrm{mm}^{2}$ and $5.990 \mathrm{~N} / \mathrm{mm}^{2}$. The max strain is about $1.637 \times 10^{-5}$ and $3.274 \times 10^{-5}$. And the max displacement is approximately $0.06 \mathrm{~mm}$ and $0.1 \mathrm{~mm}$.
\end{abstract}

Keywords- teaching aid; English class; design; SolidWorks

\section{INTRODUCTION}

There are many cards or pictures in the process of the English teaching. The cards or pictures are usually used to illustrate various regulations for college students in English class. However, there are some troubles such as tedious find, wasting time, and large amount of labor in the process of using the card. Therefore, the teaching aid in English class is needed to design in the process of English teaching [1-3].

Solidworks software is a computer aided 3D drawing tool, which developed by Solidworks Company in 1993. It has many advantages in creation of 3D model, such as grasping and using easily, system opening, etc. Solidworks software has used by many domains, such as mechanics, architect, electronics engineers, civil engineering, and light industry [4-7]. In this paper, the teaching aid in English class was designed based on SolidWorks2010. The processing for generation of teaching aid is discussed, and the distribution of the stress, strain and displacement is investigated with different load.

\section{SOLIDWOEKS SOFTWARE}

In recent years, Solidworks software is the mainstream drawing software for the design of products, and it can reveal the size, shape and position in three-dimensional space. Solidworks not only can establish the parts of the 3D model, but also has the automatic generation of the assembly. Therefore, Solidworks software is often used in mechanical design, manufacturing, aerospace, chemical and other fields. The characteristics of Solidworks software are listed as following:

1) SolidWorks has an assembly, which composed of parts:

In the assembly, it is often necessary to have additional parts or sub-systems that are not eventually used in the final system, for example (in terms of a suspension prototype): a wire jig; an extra mass; an angled blade clamp.

2) SolidWorks has a number of default settings to each of the columns in the BOM:

In the case of the Item number it will automatically choose an item number depending on the order that parts are entered into an assembly.

3) SolidWorks is easy to learn and use for consumers:

The icon design of SolidWorks is simple and straightforward, and the help file describes in detail the software operation and use. Other 3D CAD software usually takes three months for generating the drawings, while the SolidWorks software need only two weeks.

4) SolidWorks software has successfully dealt with the existence of the multiple correlations in the process of drawing, and it makes the design process simply and accurately.

The operation of SolidWorks is very simple and convenient, and the flow chart for designing the teaching aid can be described in Figure 1. Figure 1 shows that the design of the teaching aid mainly includes the design 3D outline, 3D model building, finite element analysis, and output the results. In this paper, we focus on the $3 \mathrm{D}$ model building and finite element analysis.

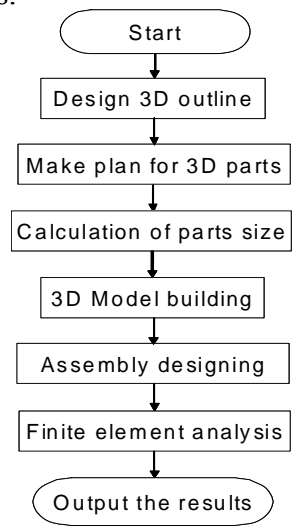

Figure 1. Flow chart for designing the teaching aid

\section{DESIGN 3D MODEL}

\section{A. Material and Load}

The material for the teaching aid is very important in the process of design. In order to carry convenient, the 
aluminum alloy 1060 was applied as the teaching aid material. The material properties are shown in Table I.

TABLE I. THE PREPERTIES OF ALUMINUM ALLOY

\begin{tabular}{|c|c|c|}
\hline No. & Item & Parameters \\
\hline 1 & Modulus of elasticity & $6.9 \mathrm{E} 10 \mathrm{~N} / \mathrm{m}^{2}$ \\
\hline 2 & Density & $2700 \mathrm{~kg} / \mathrm{m}^{3}$ \\
\hline 3 & Yield strength & $2.4574200 \mathrm{~N} / \mathrm{m}^{2}$ \\
\hline 4 & $\begin{array}{c}\text { Coefficient of thermal } \\
\text { expansion }\end{array}$ \\
\hline 5 & Thermal conductivity & $200 \mathrm{~W} /(\mathrm{m} \cdot \mathrm{K})$ \\
\hline 6 & Specific heat & $900 \mathrm{~J} /(\mathrm{kg} \cdot \mathrm{K})$ \\
\hline
\end{tabular}

The load of the teaching aid is relatively small, the normal load of the teaching aid is almost $10 \mathrm{~N}$, and the max load is approximately $20 \mathrm{~N}$. The dimension of the cards used in English class is about $220 \times 180 \times 80 \mathrm{~mm}$.

\section{B. 3D Model}

According to the load and the dimension parameters, the teaching aid is designed, and the 3D model of the teaching aid is shown in Figure 2.

The teaching aid is composed of the foundation, support bar and bracket. The foundation with dimension of $200 \times 200 \times 5 \mathrm{~mm}$ is used for fixing and supporting the teaching aid. The support bar with dimension of $\Phi 10 \times 200$ $\mathrm{mm}$ is applied for supporting the bracket. The bracket has the "T" type structure, the cards are laid on the surface of the bracket, and the dimension is shown in Figure 2.

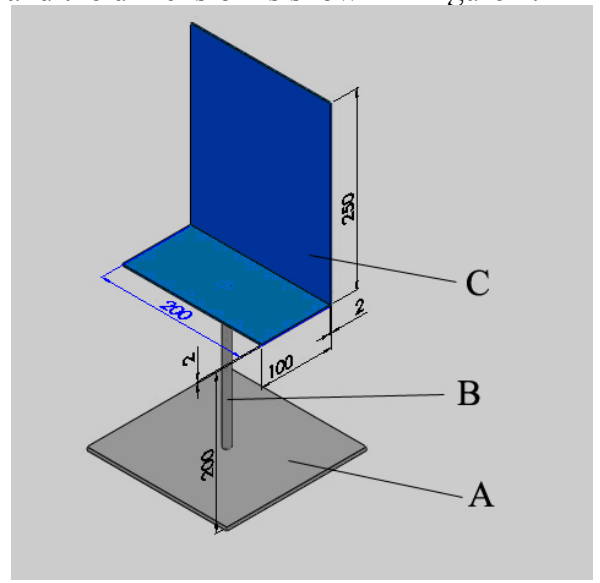

(A) Foundation, (B) Support bar, (C) Bracket Figure 2. 3D model of the teaching aid

\section{RESULT AND ANALYSIS}

\section{A. Grid Division}

The 3D model of the teaching aid is input in SolidWorks2010, and the simulation is used for grid division of the teaching aid. The result is shown in Figure 3.

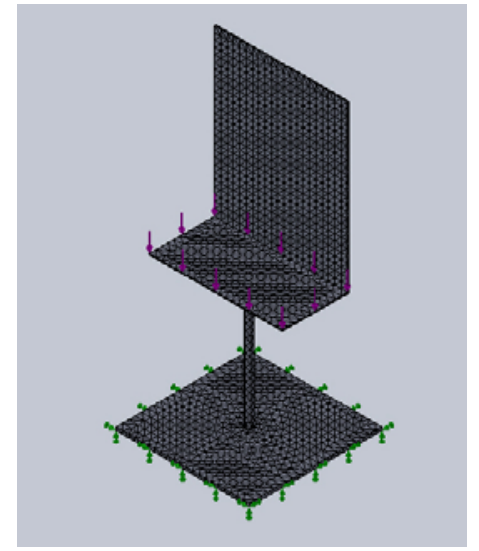

Figure 3. Grid division of the teaching aid

Figure 3 illuminates that the node number of the teaching aid is approximately 28120, and the grid unit number is 18035.

\section{B. Stress Analysis}

Figure 4 illuminates that the stress distribution of the teaching aid with different load. Figure 4(a) and (b) show the load is $10 \mathrm{~N}$ and $20 \mathrm{~N}$, respectively. When the load of the teaching aid is $10 \mathrm{~N}$, the max stress is $2.995 \mathrm{~N} / \mathrm{mm}^{2}$. While the load of the teaching aid reaches $20 \mathrm{~N}$, the max stress is $5.990 \mathrm{~N} / \mathrm{mm}^{2}$.

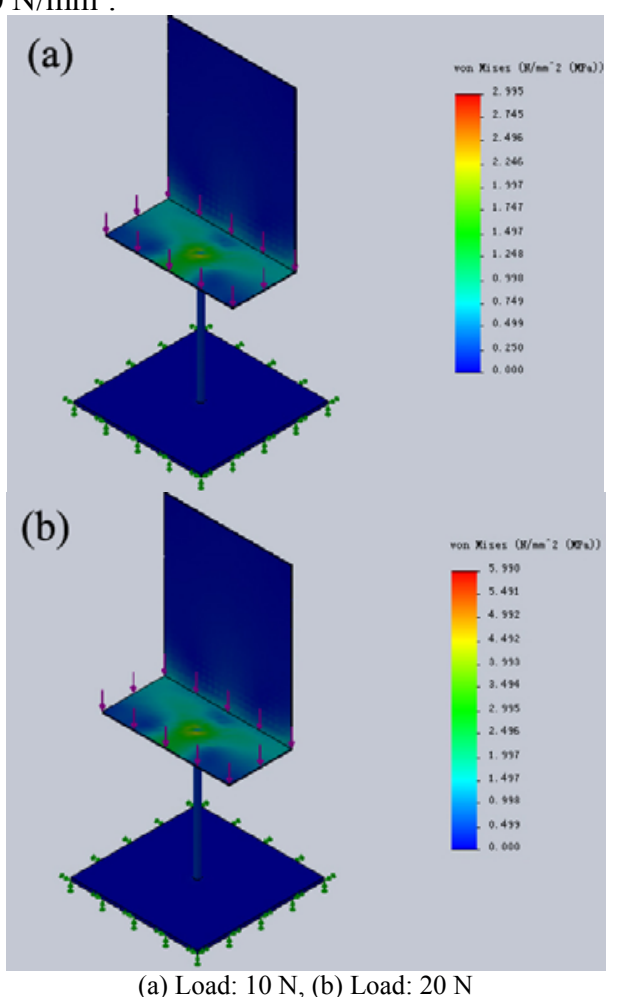

Figure 4. The stress distribution of the teaching aid 


\section{Strain Analysis}

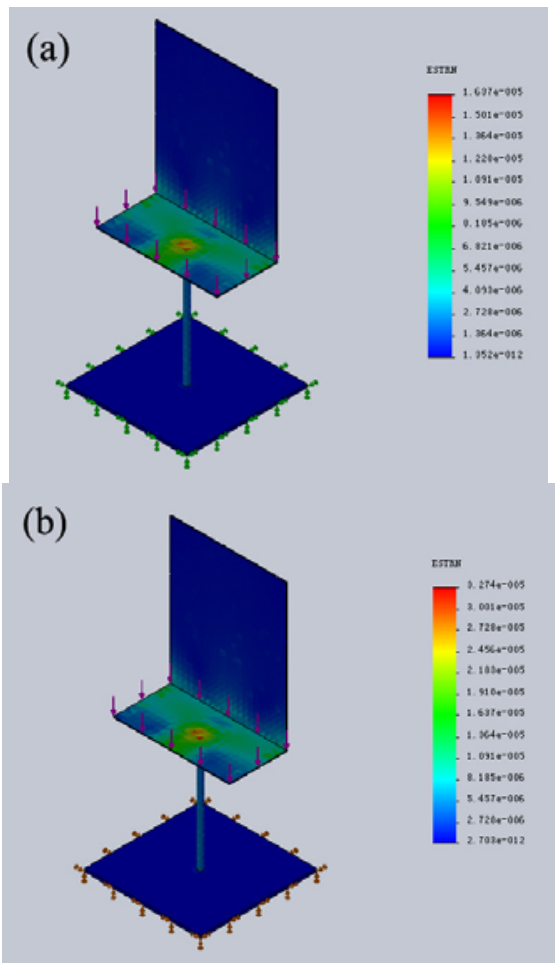

(a) Load: $10 \mathrm{~N}$, (b) Load: $20 \mathrm{~N}$

Figure 5. The strain distribution of the teaching aid

Figure 5 shows that the strain distribution of the teaching aid with different load. Figure 5(a) and (b) display the load is $10 \mathrm{~N}$ and $20 \mathrm{~N}$, respectively. When the load of the teaching aid is $10 \mathrm{~N}$, the max strain is about $1.637 \times 10^{-5}$. While the load of the teaching aid reaches $20 \mathrm{~N}$, the max strain is approximately $3.274 \times 10^{-5}$.

\section{Displacement Analysis}

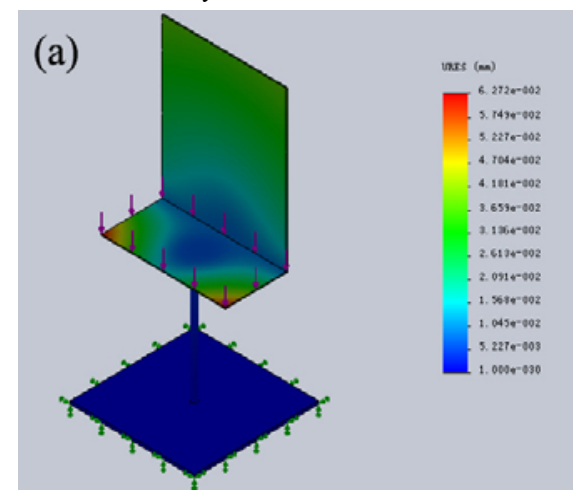

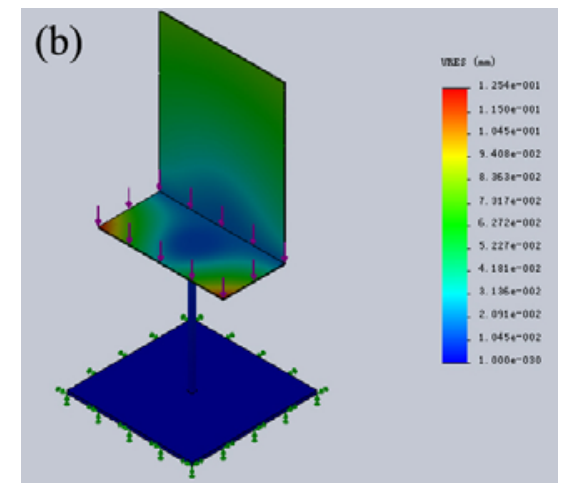

(a) Load: $10 \mathrm{~N}$, (b) Load: $20 \mathrm{~N}$

Figure 6. The displacement distribution of the teaching aid

Figure 6 explains that the displacement distribution of the teaching aid with different load. Figure 6(a) and (b) display the load is $10 \mathrm{~N}$ and $20 \mathrm{~N}$, respectively. When the load of the teaching aid is $10 \mathrm{~N}$, the max displacement is about $0.06 \mathrm{~mm}$. While the load of the teaching aid reaches $20 \mathrm{~N}$, the max displacement is approximately $0.1 \mathrm{~mm}$.

\section{CONCLUSIONS}

The teaching aid in English class was designed based on SolidWorks2010. The results indicate that the node number of the teaching aid is approximately 28120, and the grid unit number is 18035 . When the load of the teaching aid is $10 \mathrm{~N}$ and $20 \mathrm{~N}$, respectively, the max stress is $2.995 \mathrm{~N} / \mathrm{mm}^{2}$ and $5.990 \mathrm{~N} / \mathrm{mm}^{2}$. The max strain is about $1.637 \times 10^{-5}$ and $3.274 \times 10^{-5}$. And the max displacement is approximately 0.06 $\mathrm{mm}$ and $0.1 \mathrm{~mm}$.

\section{REFERENCES}

[1] H. H. Gan, Y. H., "Causal knowledge representation and nonmonotonic reasoning models in English consultant systems," Computer Sicence, vol. 28, 2001, pp. 53-55.

[2] X. B. Zhu, Q. Lin, "Evolution differences of sources of SMEs clusters competitive advantage: the case study of the weave cluster of Shaoxing in Zhejiang Province," Management World, vol. 187, 2008, pp. $75-86$.

[3] I. S. Jacobs and C. P. Bean, "Fine particles, thin films and exchange anisotropy," in Magnetism, vol. III, G. T. Rado and H. Suhl, Eds. New York: Academic, 1963, pp. 271-350.

[4] Y. H. Zhang, S. F. Yao, "A Rapid 3D modeling method to draw involute gear based on the ACD software of Solidworks and CAXA," Journal of shanxi university of science and technology, vol. 26, 2008, pp. 126-129.

[5] W.C. Lee, H. Ma, B.W. Cheng, "A heuristic for nesting problems of irregular shapes”, Comput Aided Des, vol.40, 2008, pp. 625-633.

[6] L. G. Wang, Z. J. Ma, Y. B. Jing, "Technology of the three dimensional numerical simulation with complex geological model based on the block model," Ming and metallurgical engineering, vol. 28, 2008, pp. 1-4.

[7] [2] G. Liu, R. Bai, L. Cao, "Establishment and Application of Surface Mine 3D Geological Model based on Multi DEM." Coal Engineering, vol. 382,2010, pp.73-77. 